NBER WORKING PAPER SERIES

\title{
A CROSS-MARKET COMPARISON \\ OF INSTITUTIONAL EQUITY \\ TRADING COSTS
}

Louis K. C. Chan

Josef Lakonishok

Working Paper 5374

\section{NATIONAL BUREAU OF ECONOMIC RESEARCH 1050 Massachusetts Avenue \\ Cambridge, MA 02138 \\ December 1995}

We have received many helpful comments from Gil Beebower, Gene Finn, Vasant Kamath and seminar participants at Indiana University, the 1994 Memphis State University Conference on The Competition for Order Flow, and the University of Illinois. Peng Tu provided outstanding research assistance. We thank the National Association of Securities Dealers for their support of this research; the National Center for Supercomputing Applications, University of Ilinois at Urbana-Champaign, for partial computing support; and SEI Corporation for supplying the data. We retain sole responsibility for the viewpoints expressed in this paper. This paper is part of NBER's research program in Asset Pricing. Any opinions expressed are those of the authors and not those of the National Bureau of Economic Research.

(c) 1995 by Louis K. C. Chan and Josef Lakonishok. All rights reserved. Short sections of text, not to exceed two paragraphs, may be quoted without explicit permission provided that full credit, including $\odot$ notice, is given to the source. 


\title{
A CROSS-MARKET COMPARISON \\ OF INSTITUTIONAL EQUITY \\ TRADING COSTS
}

\begin{abstract}
We compare execution costs (market impact plus commission) on the New York Stock Exchange (NYSE) and on Nasdaq for institutional investors. The differences in cost generally conform to each market's area of specialization. Controlling for firm size, trade size and the money management firm's identity, costs are lower on Nasdaq for trades in comparatively smaller firms. For the smallest firms, the cost advantage under a pre-execution benchmark is 0.68 percent. However, trading costs for the larger stocks are lower on NYSE. For the largest stocks, costs are lower by 0.48 percent on NYSE. Given the extreme difficulty of controlling for variables other than market structure, however, comparisons of costs should be interpreted with extreme caution.
\end{abstract}

Louis K. C. Chan

Department of Finance

College of Commerce and

Business Administration

University of Illinois

1206 South Sixth Street

Champaign, IL 61820
Josef Lakonishok

Department of Finance

College of Commerce and

Business Administration

University of Illinois

1206 South Sixth Street

Champaign, IL 61820

and NBER 
The mechanisms for trading stocks have undergone dramatic changes in recent years. In the traditional floor-based trading system, as exemplified by the New York Stock Exchange (NYSE) or the American Stock Exchange (AMEX), all trades in a stock are centrally processed by a specialist. More recent screen-based systems (such as the Nasdaq system) feature several market-makers for each stock. Proponents of the multiple dealership system on Nasdaq argue that competition among dealers lowers trading costs for investors. Echoing these arguments, the stock exchanges of many countries have begun to move to a screen-based dealer system, so that the exchange floor is becoming a thing of the past.

Yet in one respect the trend towards dealership systems presents a puzzle. There is a widespread popular perception that investors' trading costs are in fact higher on the Nasdaq market, the claimed advantages of competition notwithstanding. This perception is, for instance, provocatively described in a recent article in Forbes, where a trader is quoted as remarking that "in the overthe-counter market, the competition is between the dealers and the customer" (Morgenson (1993)). The available scientific evidence on differences in trading cost between the NYSE and Nasdaq, based on a wide range of methodologies and samples, generally finds that on Nasdaq the bid-ask spreads are wider. Price improvement, the ability to execute at better than the posted quotes, also appears to be more limited on Nasdaq. ${ }^{1}$ It may be the case, of course, that the trend towards the Nasdaq dealership system is short-lived. Given the cost-consciousness of the investment industry, however, it is curious how an apparently more costly trading mechanism has thrived for so long and even expand.

Several arguments can be made on behalf of the NYSE specialist system. ${ }^{2}$ Limit orders that take priority over the specialist and that can be crossed with other public orders, as well as trading with the "crowd" at the specialist's post, compete with the NYSE specialist in providing liquidity. Conversely, Nasdaq dealers generally play a larger role as principals in public trading (relative to the NYSE specialist), so that investors may have to bear more frequently the cost of committing the dealer's capital. ${ }^{3}$ On a more speculative level, it might be argued that dealers find it necessary 
to build long-term relationships with one another for a variety of reasons. Since order flow and information tends to be more fragmented when there are multiple market makers, dealers may cooperate to circumvent adverse selection problems with informed public traders. Also, an individual market-maker's inventory is often insufficient to fill a large customer's order. These long-term relations may perhaps blunt competitive pressures. Yet another possibility is that if trading costs differ across different types of stocks (for example, stocks of small companies and stocks of large companies), competition among the different markets forces each type to gravitate to whichever market offers the largest net benefits. Different market structures may co-exist, each with a comparative advantage in trading different types of equities.

Any direct empirical comparison of spreads across markets is also fraught with difficulties. Unlike the NYSE, prices on Nasdaq are quoted net of commissions (at least for large investors), and many trades on both markets occur within the spread. It is necessary, in general, to take into account the depth (quantity of shares available) at the posted quotes on each market. The characteristics of the stocks listed on the two markets, such as their market capitalization, industry affiliation, and trading volume, are also very different. More importantly, the available empirical studies do not directly address the issue of trading costs from the perspective of a very large and influential component of the market, namely institutional investors. ${ }^{4}$ Large investors are probably in a better position to play off one dealer against another and thus trade within the posted spreads. For these institutions the posted spreads may not be the most informative measure of trading costs. The Forbes article, for example, notes that "Not everyone pays more for using Nasdaq. Institutions and big traders can...[circumvent] spread-hungry dealers" (Morgenson (1993)). If large investors indeed benefit from lower trading costs (at least for some issues) on Nasdaq, then these benefits may be an important force driving the popularity of screen-based dealership systems. In short, the issue deserves further study.

This paper explores empirically the difference in execution cost (commission cost and market impact cost) between issues listed on the NYSE and issues listed on the National Market System 
of the Nasdaq market. In contrast to many previous studies, our analysis is based on the actual trading behavior of a large sample of institutional investment managers. From the standpoint of such an institutional investor wishing to buy and sell a given-sized order in a given type of stock, a key question is which market allows the order to be completed with minimal disruption in the price. By examining the transaction prices achieved by this group of active, sophisticated investors on each market, this research provides a unique perspective on differences between the costs of liquidity on the NYSE and Nasdaq.

Two cautionary remarks are in order at the outset. First, since our sample is based on the trades of institutional investors, our results cannot be directly extrapolated to the trading costs faced by individual investors. We conjecture that comparisons of spreads may be a more relevant measure of trading costs for small traders. Secondly, it would be an extremely ambitious and difficult task to evaluate the operating efficiency of any market. There is no reason to believe that it is any easier to assess the quality of a stock market. For one thing, trade execution is not the only dimension for evaluating dealers' services. From the standpoint of a company choosing where to list, for instance, a small firm may prefer to be listed on Nasdaq, where the market-maker has a stronger incentive (compared to the exchange specialist) to publicize the stock and disseminate information to investors. Even if one were to focus on the quality of execution services, there is no concensus on how to measure trading costs or on how to control for the innumerable influences on trading activity and price movements. It is also no easy task to sort out the message from all the noise in stock price movements. ${ }^{5}$ It is true that transactions data yield a very large number of observations to work with, but the apparent size of the sample may provide a false sense of confidence, since the observations cannot be considered independent by any stretch of the imagination. It is unrealistic, then, to expect any unqualified verdict as to what trading system offers lower trading costs.

Our main findings are as follows. After controlling for numerous confounding factors, there is no evidence that one exchange uniformly dominates the other in terms of providing lower execution costs. Instead, the cost differences seem to sort themselves out along each marketplace's niche. 
Institutional trading costs for relatively smaller firms (with 1991 market capitalization below $\$ 1.2$ billion) are lower on Nasdaq. These issues account for 88 percent of the number of Nasdaq trading programs, or 69 percent of the dollar value traded. In the case of the smallest firms (with market capitalization less than $\$ 180$ million) for instance, the cost of buying and selling (a round-trip transaction) are lower on Nasdaq by 0.68 percent under a pre-execution benchmark, or 0.20 percent lower under a post-execution benchmark. Taking commission rebates for NYSE issues into account may, however, reduce this cost advantage for Nasdaq, especially in the case of the smaller stocks. On the other hand, trades on the NYSE are more concentrated in the larger issues. For example, transactions in the very largest stocks (with market capitalization above $\$ 4.5$ billion) make up 32 percent of the number, or 51 percent of the value, of NYSE trading programs. The NYSE has a round-trip cost advantage for these stocks of 0.48 percent under a pre-execution benchmark, or 0.14 percent under a post-execution benchmark.

The rest of the paper is organized as follows. Section I of the paper describes our data set, and our different measures of execution cost. The empirical results are presented in section II. Section III uses a regression model to compare costs across the two markets. Section IV summarizes and concludes the paper.

\section{Methodology}

\section{A. Description of sample}

Our data set records the transactions made by each of 33 large investment management firms every day from January 1989 to December 1991. The managers in the sample follow a variety of different investment styles and different trading strategies. Their trades, both large and small, involve issues listed on the NYSE, Amex and the Nasdaq National Market System. In total, there are roughly 1.7 million transactions. For each trade, the stock's CUSIP number, the trade date, number of shares, and gross dollar commissions are recorded. In addition, each trade is identified as a purchase or 
sale by the investment manager, who in turn is also identified by a numeric code (although the name of the management firm is confidential). These data are collected by SEI Corporation, a large organization specializing in the area of financial services primarily for institutional investors. We supplement these data with transaction data from the Francis Emory Fitch Company, and data from the Center for Security Prices at the University of Chicago.

\section{B. Trade packages}

Analyses of trading have to take into account the fact that institutional investors commonly break their orders up into successive trades that may run over several days (see Chan and Lakonishok (1995), Keim and Madhavan (1995) for evidence). Even if an investor's original trading intentions could be quantified, data on investors' ex ante orders are not readily available. Instead, we construct a proxy for a manager's order in a stock in the following manner. Specifically, we define a "buy package" to be a case where the same manager carries out successive purchases of the stock for a specified period of time. Based on our discussions with money managers and traders, we choose a five-day break to end a package (although we have also replicated the results with packages defined by shorter gaps in trading). "Sell packages" are defined similarly. To illustrate, suppose a manager buys a stock for three days in a row and then, after a one-day pause, engages in another buy transaction in the stock. Suppose also that there are no further trades in this stock by this manager. Then all of these trades are considered part of one package under our definition. Chan and Lakonishok (1995) provide a detailed description of the concept of trade packages.

\section{Measuring execution cost}

The basic unit of analysis in our examination of institutional trading costs is a trade package. When we measure the execution cost of a package, all trades in the package are evaluated against a common benchmark price. Doing otherwise will lead to misleading inferences. Suppose each trade in a package is treated individually and compared with some benchmark price on the trade date 
(as is commonly done in practice). Such an analysis reveals zero impact cost if the manager on average buys at the benchmark price. However, the manager's buying pressure can be pushing up the benchmark price over the course of trading, and in fact, the package may be very costly if the trades were compared to a benchmark price established before the initiation of the package.

A key difference between the NYSE and Nasdaq is that no commissions are reported on Nasdaq trades, because institutions deal net with market-makers. The observed execution price thus incorporates a commission component. Conversely, the commission charge is separated from the execution price for NYSE transactions. One unique aspect of our data set is that we know the gross dollar commissions paid for each trade. This lets us adjust execution prices for trades in NYSElisted stocks to incorporate the commissions paid (ignoring soft-dollar rebates), so as to put costs on the same footing across the two marketplaces. Our results thus compare the total execution costs (price impact and commission) across the two markets.

The first step of our cost calculations is to compare the trade price (adjusted for commissions) to a benchmark price. In the second step, we adjust this gross cost to remove any market-wide price movements. It is generally not possible to single out one price as being the most appropriate benchmark to use in the first step. Instead, we employ two benchmarks: a pre-execution benchmark and a post-execution benchmark. Chan and Lakonishok $(1993 \mathrm{~b}, 1995)$ discuss the relative merits of these and other benchmarks.

Under the first benchmark, we calculate for each trade in a package the percentage price change from the opening trade price on the first day of a package to the trade's execution price. If the portfolio manager's trading intentions were known at the beginning of the package's first day, the price at the open of trading could have been captured (at least for small trades). However, any difference between the trade price and the benchmark may also partly reflect market-wide price movements that are unrelated to trading activity. In order to adjust for such price movements, when each trade in a package is executed we act as if we simultaneously invest in a portfolio of stocks with similar equity market capitalization, and hold it until the completion of the package. 
The price impact for each trade in a package is measured in excess of the return on this size control portfolio. We then weight each trade's excess price impact by the trade's dollar value (principal value) relative to the package's total value, and sum the weighted percentage price impacts across all trades in the package to yield the package's cost.

An alternative benchmark price can be taken from the period subsequent to the completion of the package, once the temporary price pressure from the package has eased. Our second cost variable measures the percentage return from the execution price of each trade in a package to the closing trade price five days after the package's last day and adjusts for the return over the corresponding period on a size control portfolio. The package's cost is the weighted average of the component trades' excess returns, where the weights are given by the trades' relative principal values. There is a natural interpretation to costs measured relative to such a post-execution benchmark: if purchases (sales) are accomplished at prices below (above) their values after the trading pressure has waned, then the package has added value (generated an "abnormal" return) and the manager does not regret carrying out the trade. Because the post-execution benchmark is not established until after a package has ended, it has the added virtue that it cannot be easily "gamed." If, on the other hand, traders are evaluated against a benchmark that is known before they trade, they can appear to perform favorably by deferring trades until they can do better than the known benchmark.

The procedure for calculating the return on the size control portfolio is as follows. At the beginning of each quarter, we calculate the decile values of the distribution of market value of outstanding equity for NYSE stocks. All NYSE and Nasdaq stocks are then ranked by equity market capitalization and assigned to one of ten portfolios, based on these decile values. Rather than assuming that the control portfolio is periodically rebalanced, we calculate the buy-and-hold return for each stock in the portfolio, using different holding periods (from one to thirty days long). The return for the control portfolio is the equally-weighted average of the component stocks' buy-and-hold returns. 


\section{Results}

\section{A. Descriptive statistics for institutional trading activity}

Table I describes our sample. We classify a package in a stock as either a NYSE, Amex or Nasdaq package, depending on where the stock is listed (which may be different from where the package is executed). For each market, we provide descriptive statistics for the aggregate and also for trades classified by firm size (the equity market capitalization of the stock traded). The classifications for firm size are based on the cut-off values from the distribution of market capitalization for NYSE stocks only, and are updated at the beginning of each quarter. The size classifications are as follows. Group 1 (the smallest firms) comprises all firms with market capitalization below the thirtieth percentile of the size distribution of NYSE firms; group 2 comprises firms between the thirtieth and fiftieth percentiles of the size distribution; group 3 comprises firms between the fiftieth and seventieth percentiles; group 4 comprises firms between the seventieth and ninetieth percentiles. Firms with equity market capitalization in excess of the ninetieth percentile of the NYSE size distribution are placed in group 5. We adopt these non-uniform size classifications to ensure that there will be a meaningful number of packages in both the smallest and the largest firms.

Our sample is much larger than those in many previous studies. Combining both purchases and sales yields a total of 166 thousand packages worth $\$ 197$ billion for NYSE issues, and 68 thousand packages worth $\$ 39$ billion for Nasdaq issues. The sample is much more sparse with respect to issues on the American stock exchange, and the numbers are presented only for the sake of comprehensiveness. Hereafter we focus only on NYSE and Nasdaq issues. Trading in NYSE issues is concentrated in the two groups of the largest firms (size groups 4 and 5). These groups, comprising firms with 1991 equity market capitalization above $\$ 1.2$ billion, make up 67 percent of the total number of NYSE packages, and 84 percent of the NYSE total dollar value traded in our sample. In contrast, Nasdaq trading is more heavily represented in the first three size groups, which constitute 88 percent of all Nasdaq packages, or 69 percent of the Nasdaq total dollar value 
traded.

Table II describes several characteristics of trade packages, for buys and sells separately. Beyond their roles as summary statistics, these characteristics also merit attention from the standpoint of assessing liquidity on each market. Specifically, insofar as this set of sophisticated traders tailor their transactions to reflect the different conditions on each market, these characteristics also convey some sense of the "perceived liquidity" on each market. For instance, it is commonplace to observe that trades in low-capitalization stocks tend to be smaller than trades in larger stocks. These differences in trade size simply reflect the differences in the perceived liquidity of the market for small and large stocks. Three descriptive measures are provided in Table II - the dollar value of a package, package size relative to outstanding equity, and the duration of a package. ${ }^{6}$ Duration is the weighted average of the number of elapsed trading days from the package's first day to each trade in the package. The weight for each trade is its principal value relative to the package's value.

What is striking in Table II is that, under these measures, perceived liquidity on Nasdaq is no lower than on the NYSE. Even in the largest stocks, Nasdaq packages are larger than NYSE packages: the average package size on Nasdaq is $\$ 2$ million for buys (versus $\$ 1.7$ million on NYSE) and $\$ 2.6$ million for sales (versus $\$ 2$ million on NYSE). At the other end of the scale, average package size for the smallest firms is roughly comparable between the two markets, even though low-capitalization Nasdaq firms are likely to be still smaller (and hence lower-priced) than their NYSE counterparts. Expressing package size relative to outstanding equity (panel B) confirms this impression. Nasdaq packages in size category 1 on average make up about 0.4 percent of outstanding equity for buys ( 0.5 percent for sells), compared to about 0.3 percent on NYSE. The duration, or average length of time taken to complete a package, also tends to be shorter for Nasdaq packages, particularly for relatively small companies (in size categories 1 to 3 ). Based on their trading patterns at least, large, sophisticated institutional investors do not act as if they perceive liquidity to be lower on Nasdaq. 


\section{B. Round-trip execution costs}

We calculate costs separately for purchases and for sales. Since our intent is to compare the overall cost of liquidity on each market, however, we report only the cost of a round-trip (purchase and sale) transaction, as obtained by adding the separate costs for buys and for sells. As a preliminary to our cost comparisons, we first calculate the round-trip execution costs across all the packages on each market. Any comparison at the aggregate level is simplistic, however, because the differences between the trading mechanisms of the NYSE and Nasdaq are confounded by other influences - for example, the two markets differ dramatically with respect to the sizes of the listed issues. Nonetheless, such a casual comparison has received the bulk of attention in the popular press, so we use it as a starting-point. Under a pre-execution benchmark (the opening price on the package's first day'), Nasdaq packages are much more costly than NYSE packages: the median round-trip cost is 0.99 percent on Nasdaq versus 0.54 percent on NYSE. There is less of a difference between the two markets with respect to the median round-trip cost under a post-execution benchmark (the closing price five days after the package's last day), although the cost is still higher on Nasdaq (0.47 percent, compared to 0.36 percent on the NYSE). We use median costs in our analysis to mitigate the effects of extreme observations since, even with so many observations, the costs are affected by factors unrelated to trading activity.

\section{B.1. Cost comparisons controlling for firm size and trade size}

Any conclusions based on the above aggregate costs would, however, be premature, if only because the typical Nasdaq company is much smaller than the typical NYSE company. Our next research design follows the lead of prior empirical and theoretical research, and provides a fairer comparison by controlling for the effects of firm capitalization and relative trade size. We interpret relative package size as an indication of the complexity of the trade. Larger packages are generally more difficult to execute and incur a higher cost, either because larger trades are associated with more severe problems of adverse selection, or because they impose more demands on liquidity. 
We first classify packages into one of five categories according to market capitalization of the issue. Within each size category, packages are further classified by relative trade size, measured as package size relative to outstanding equity of the stock, to one of five groups. The classification by complexity within each size category is as follows. Complexity group 1 ("easy" packages) is made up of packages below the median when ranked by relative package size; group 2 comprises packages whose relative size falls between the median and the third quartile; group 3 comprises packages whose relative size falls between the third quartile and the ninetieth percentile; group 4 comprises packages whose relative size falls between the ninetieth and ninety-fifth percentiles. Group 5 ("difficult" packages) contains the largest five percent of packages when ranked by relative size. We adopt this classification in order to obtain a roughly comparable amount of dollar principal traded in each category. Similar results are obtained when package size is measured relative to the stock's float.

The size-complexity split yields twenty-five different cells. Table III provides some background for our cost calculations by reporting the number of packages, and the dollar value traded, in each cell for each market. While the two-way classification provides a fairer comparison of the two markets, it comes at a cost: the number of observations differs across cells, and in particular some cells are very sparsely populated. The number of NYSE packages traded in the smaller companies (size groups 1 and 2) is not large to begin with, and there are still fewer observations on the more difficult trades for these firms. For instance, in size group 1 there are roughly three hundred or fewer packages falling in each of complexity groups 4 and 5 . On Nasdaq, the sample size is about a thousand or less observations in eleven out of the twenty-five cells, and the count is particularly low for larger firms and complicated trades. In general, then, it is inadvisable to emphasize a cell-by-cell comparison of costs; rather we focus on broad patterns across the cells.

Table IV reports for each cell the median across all managers' cost of executing packages on each market. Under a pre-execution benchmark (panel A), the median round-trip (buy and sell) cost for NYSE packages ranges from 0.40 percent for easy trades in large stocks to 4.85 percent 
for difficult trades in small stocks. On Nasdaq, the corresponding costs are 0.77 percent and 3.78 percent, respectively. Out of 25 cells, the costs are lower for Nasdaq in 13 cases. These cases comprise $74 \%$ of the number, or $53 \%$ of the value, of Nasdaq packages. Conversely, the 12 cells where costs are lower on NYSE make up $63 \%$ of the number and $80 \%$ of the value of NYSE packages. To help summarize the table, we also present the equally-weighted average down all rows in each column or size category, and across all columns in each row or complexity category. The cases where Nasdaq has a cost advantage tend to be concentrated in the smaller firms (size categories 1 to 3). The cost advantage is particularly notable for the smallest firms in size category 1: Nasdaq has a commanding lead over NYSE in every complexity group for these firms, and the average cost advantage is in excess of one percent. ${ }^{7}$ The lead passes over to the NYSE, however, for the largest firms in size categories 4 and 5 . Costs are lower in almost every complexity group for these categories, and the NYSE's average cost advantage is 0.33 percent.

The results using a post-execution benchmark (panel B) tend to be more favorable towards Nasdaq. There are 15 out of 25 cells (representing $86 \%$ of the number, or $63 \%$ of the value, of Nasdaq packages) where the cost on Nasdaq is lower than the cost on NYSE, or where there is even a larger round-trip benefit (negative cost) on Nasdaq. In the remaining ten cases (where $51 \%$ of the number or $56 \%$ of the value of NYSE packages are concentrated), execution costs are lower on the NYSE. In other respects, the results under a post-execution benchmark confirm that packages for smaller firms (perhaps even up to size category 4) generally tend to be associated with lower costs on Nasdaq. In particular, round-trip costs under a post-execution benchmark in size group 1 are lower on Nasdaq than on NYSE by an average of 0.8 percent. In size group 5, however, round-trip costs are lower on NYSE than on Nasdaq by an average of 0.34 percent. One puzzling feature of the costs measured under a post-execution benchmark, however, is that they appear to be only weakly related with either firm size or trade complexity. In comparison, the costs under a pre-execution benchmark in panel A generally move in the expected direction with firm size and trade complexity. In the subsequent discussion, we will emphasize the results using a pre-execution 
benchmark. $^{8}$

\section{B.2. Cost comparisons controlling for firm size, trade size and money manager}

One confounding influence not accounted for in Table IV is the identity of the management firm undertaking the package. Different managers may concentrate their trades on different markets. Of all the explanatory variables considered in Chan and Lakonishok (1993b,1995), the manager's identity, which generally reflects differences in skill or the underlying demand for immediacy, plays the strongest role in explaining execution costs. To control for this influence, we consider within each size-complexity classification packages executed by the same manager, and calculate the difference in median costs across the two markets for that manager. We limit attention to only those managers who carried out at least ten packages in that size-complexity cell and who traded on both markets. Table V reports the median of these cross-market differences over the managers within each sizecomplexity classification. Each number thus represents the typical difference in execution cost across the two markets, incurred by a typical manager trading comparably-sized packages in issues of comparable market capitalization. Our comparison of markets based on this sample of packages matched by size, trade complexity and the identity of the manager thus captures most of the directly relevant characteristics of trades and should permit a clearer evaluation than has been possible in the existing literature.

Using a pre-execution benchmark (panel A), execution costs are lower on Nasdaq for thirteen out of the twenty-five cells. Our main finding is that the NYSE appears to dominate for packages in the larger firms. In size groups 4 and 5 , costs are lower on the NYSE for all but one complexity group (and in the latter case the difference is close to zero). Average execution cost for these companies is lower on the NYSE by more than 0.3 percent. On the other hand, Nasdaq seems to have the advantage for packages in size groups 1 to 3 . The average cost savings for these firms on Nasdaq ranges from 0.68 percent for the smallest firms (category 1) to 0.14 percent for firms in size group 3. When a post-execution benchmark is used (panel B), Nasdaq tends to display a cost 
advantage in more cells, compared to panel A (costs are lower on Nasdaq for nineteen cells in panel B). Nasdaq delivers lower trading costs for the smallest companies (by 0.20 percent on average), and also for companies in size categories 2 to 4 . Nonetheless, the NYSE's cost advantage for the largest firms (size group 5) persists.

Tables IV and V thus agree, at least qualitatively, on Nasdaq's cost advantage for the smallest companies in size group 1. It is perhaps not coincidental that the bulk of Nasdaq packages are indeed concentrated in firms belonging to this size category. The two tables also confirm qualitatively that execution costs for the largest firms in size group 5 are lower on the NYSE. Again, this finding is compatible with the fact that companies in this size group account for much of institutional trading on the New York exchange. The cost differences in the tables are thus consistent with each market's perceived area of specialization. By the same token, any inferences about trading costs for the largest Nasdaq companies in size group 5 should be treated with great caution. There are only 1,800 packages in this category, and they are concentrated in a very small number of issues - in 1991, for example, only seven Nasdaq firms fall in this size range, and they represent a very limited set of industries. At the same time, inferences with respect to the smallest firms (in group 1) for the NYSE may also be imprecise, although the number of packages in this category is not small $(9,100$ packages $)$.

\section{Regression analysis}

\section{A. Regression for overall sample}

As an additional effort to control for confounding influences, we fit the following regression model:

$$
\begin{aligned}
c_{i}= & \alpha_{0}+\beta \mathrm{LOGSI}_{i}+\gamma \mathrm{COMP}_{i}+\sum_{j=2}^{33} \delta_{j} \mathrm{M}_{i j} \\
& +\sum_{j} \phi_{j} \mathrm{NDD}_{i j}+\pi_{1} \mathrm{LOGP}_{i}+\pi_{2} \mathrm{VOL}_{i}+\pi_{3} \mathrm{DUR}_{i} \\
& +\sum_{j=1}^{9} \alpha_{j} \mathrm{NASD}_{i j}+\epsilon_{i}
\end{aligned}
$$


where $c_{i}$ is the cost for the $\mathrm{i}$-th package. The first set of explanatory variables reflects the influences already discussed: $\mathrm{LOGSIZ}_{i}$ is the logarithm of the equity market capitalization (at the end of the prior quarter) of the stock traded; $\mathrm{COMP}_{i}$ is package size relative to shares outstanding at the end of the prior quarter, and the dummy variables $\mathrm{M}_{i j}$ represent manager-specific effects. The regression also introduces several variables that are not controlled for in the previous sections. Specifically, Nasdaq companies tend to be younger, more volatile stocks with a tilt towards certain sectors (for example, technology stocks). Accordingly, equation (1) takes into account: t stock's industry affiliation, as given by dummy variables $\mathrm{IND}_{i j}$ for 2-digit SIC code classifications; LOG $\mathrm{P}_{i}$, the logarithm of the stock's price at the end of the prior quarter; $\mathrm{VOL}_{i}$, the volatility of the underlying stock traded (measured as the standard deviation of daily returns over the prior quarter); and package duration $\mathrm{DUR}_{i}$.

Of particular concern here is the effect of exchange affiliation on cost. Since this effect is not likely to be uniform across all types of trades, it is necessary to introduce interaction terms. Specifically, in equation (1) we let the exchange effect interact with the effects of firm size and package complexity. At this detailed a level of comparison, however, the coefficient of each dummy variable for the exchange effect may be estimated with a great deal of noise if we maintain our twenty-five classifications by size and complexity. As one compromise, we aggregate the size and complexity breakdown as follows. In equation (1), there are three categories of firm size (small, medium and large). Small firms comprise size groups 1 and 2; the medium category comprises size group 3 , while large firms combine size category 4 and 5 . Within each size category, packages are classified as easy (corresponding to complexity groups 1 and 2), moderate (corresponding to complexity group 3) and difficult (combining complexity group 4 and 5). Within each of the resulting nine categories, the dummy variable for the exchange, $\mathrm{NASD}_{i}$, takes a value of one if the package is for a Nasdaq issue and zero otherwise.

To mitigate the effects of outliers on (1), we Winsorize all observations on the dependent variable to their fifth or ninety-fifth percentiles. The regression is fit separately for purchases and sales. 
Then we add the coefficients of each variable across the two equations in order to evaluate each variable's impact on the cost of a round-trip execution. Panel A of Table VI reports the coefficients for the non-exchange effects (for the sake of brevity we do not report the coefficients for the industry or manager effects). The signs of the coefficients for firm size, relative trade size and volatility all conform to intuition. On the other hand, costs measured relative to the pre-execution benchmark tend to be positively associated with the level of the stock price, and positively associated with the package's duration. Given the correlation between the explanatory variables, however, it may not be possible to disentangle each variable's influence. Further, the regression already controls for firm size, package size as well as the manager's trading style through the dummy variable for each manager, so the interpretation of the coefficients for the price level and duration is somewhat more complicated. For instance, it may be the case that, other things equal, the lack of liquidity in a stock and its relatively higher cost of execution may require the package to be worked over a longer period of time, resulting in a longer duration.

The coefficients for the exchange effect are reported in panel B of Table VI. Note that these estimated cost differences are not directly comparable to the results reported in the earlier tables on several accounts: the earlier results are based on median or dollar-weighted costs, while the coefficients of the dummy variable for the exchange are based on a least-squares fit; the regression introduces additional controls, and the size-complexity partitions are different.

If a pre-execution benchmark is used, the results tend to confirm the overall impression from the preceding tables. In particular, costs for trading small firms are lower on Nasdaq by $0.25 \%$ for the easiest packages. There are also cost savings, but of smaller magnitude, for trades of low or moderate complexity for medium-sized and large firms on Nasdaq. Together, the easiest trades comprise $72 \%$ of the number, and $16 \%$ of the value, of Nasdaq packages. However, the largest packages on Nasdaq are associated with a cost penalty in excess of one percent for all three categories of firm size. ${ }^{9}$ These large packages make up $11 \%$ of the number ( $61 \%$ of the value) of Nasdaq trades. The category of the largest packages, where the NYSE generates cost savings, constitute $9 \%$ of the 
number and $67 \%$ of the value of exchange-listed trades. As in the earlier tables, the post-execution benchmark is kinder towards Nasdaq, giving it the advantage in seven out of the nine cases.

The higher cost on Nasdaq for large trades, relative to the NYSE, stems possibly from differences in the mechanisms for executing large trades on the two markets. On the NYSE, large or difficult transactions are generally accomplished through a block broker on the upstairs market, who "shops the block" and solicits interest from other investors who may be more natural suppliers of liquidity. Typically, the block broker serves only as an agent for the investor and does not take a position in the stock, receiving instead only commission income. There is, however, on the Nasdaq market no corresponding central message post where prices and order flows can be concentrated. For a Nasdaq issue, therefore, a dealer is more likely to be involved as a self-interested principal, either as a market-maker or as a contraparty in a block trade. The relation between an investor and a dealer on the over-the-counter market is thus more likely to be adversarial in nature. Given the difficulty of assessing the quality of execution for large or complicated trades, the dealer has greater leeway in increasing its profit margin at the expense of the investor.

As one check on the robustness of the regression model, we break the overall sample period into two halves, and fit the regression model over each sub-period. Panel $\mathrm{C}$ of Table VI reports the coefficients of the exchange dummy variables (added across the equations for purchases and for sales) in each sub-period. For the pre-execution benchmark, there is some indication that costs are higher in the second sub-period. In general, however, there is no clear trend over time in the cost differences across the two markets.

While the rich features of our dataset and its size allow us the luxury of controlling for a much more expanded set of variables in equation (1) than hitherto possible, it is still debatable whether the resulting inferences are more reliable than those from the sample of matched trades in our earlier tables. Introducing successively more refined controls whittles away at the effective sample size (even if we were to assume that the observations are independent), so that the final inferences may be based on a very limited range of comparisons. Moreover, the regression model imposes a 
simple linear functional form on what is inherently a complex relation. The regression may thus provide a false sense of confidence, so we treat it as a complement rather than as a substitute for the cost comparisons in the earlier tables.

\section{B. Regressions for individual money managers}

One drawback of equation (1) is that it constrains the average cost difference across markets to be constant, given firm size and trade complexity, regardless of the money manager's investment and trading styles. Evidence in Chan and Lakonishok (1995) attests to the importance of the manager's style for trading costs. To provide some further perspective on the range of variation in costs across the variety of trading behavior, we fit a variant of equation (1) to each manager's buy packages and sell packages separately. The regression retains all the explanatory variables in (1) except the dummy variables for the manager effects; to prevent overfitting we include only one dummy variable to represent the effect of the exchange. Adding the coefficients of this exchange dummy across a manager's equations for purchases and for sales gives the average difference between NYSE and Nasdaq in round-trip execution cost for that manager, all other things equal. By proceeding in this manner for each money manager, we can build up the distribution of cross-market cost differences over our sample of 33 money managers.

Panel A of Table VII provides the results. The average round-trip execution cost under a pre-execution benchmark is higher on Nasdaq by $0.16 \%$ for our sample of money managers (after taking into account the other variables in the regression). The median is quite similar (0.13\%). The average or the median, however, masks considerable variation: the 25 th and 75 th percentiles of the distribution of the exchange dummy's coefficient across managers are $-0.20 \%$ and $0.44 \%$, respectively. Put another way, 21 of the money managers in the sample experience higher regressionadjusted costs on Nasdaq, while 12 managers benefit from lower costs. Using a post-execution benchmark, our regressions suggest that the average round-trip cost is lower on Nasdaq by $0.12 \%$ on average (although the median indicates a slighly higher cost of $0.02 \%$ on Nasdaq). Although the 
number of managers with higher costs roughly matches the number with lower costs, the magnitude of the differences varies from $-0.41 \%$ for the first quartile to $0.30 \%$ for the third quartile.

\section{Conclusions}

There has been much heated controversy concerning the costs incurred by investors on different markets, and serious accusations of poor execution quality have been levelled against the Nasdaq market. More generally, the relative merits of a specialist system (such as the NYSE) versus a dealer system (such as Nasdaq) continue to be debated. It would be surprising to find, however, that such an apparently costly market has managed to survive and even expand, given the cost-consciousness of the professional investment industry.

This paper uses a unique dataset that reports the trades executed by a large sample of institutional investors to compare execution costs (market impact plus commission costs) on the NYSE and on Nasdaq. Since the stocks traded on the two markets differ along many dimensions, it is not generally possible to conduct a controlled experiment to compare costs. Based on the trading behavior of these large, sophisticated investors, however, we find no evidence that they perceive liquidity to be lower on Nasdaq than on the NYSE.

The cost differences that we detect also conform to the perceived areas of specialization on each market. After taking into account firm size, package size and the identity of the money management firm, institutional investors generally pay lower costs on Nasdaq when they trade comapratively smaller firms in size categories 1 through 3 (with 1991 market capitalization below $\$ 1.2$ billion). These trades make up $88 \%$ of the number, and $69 \%$ of the value, of Nasdaq packages. For the smallest firms (size category 1), in particular, the cost advantage under a pre-execution benchmark (the opening price on the package's first day) is 0.68 percent. However, the costs of trading the larger stocks in size categories 4 and 5 (which make up $67 \%$ of the number, and $84 \%$ of the value, of NYSE packages) are lower on NYSE. For the largest ten percent of NYSE-listed stocks (size category 5 , comprising firms with market capitalization above $\$ 4.5$ billion), costs are lower by 0.48 
percent. In the context of a regression model where we introduce additional controls for industry affiliation, the level of the stock price, volatility and package duration, we do not find that costs are uniformly higher on one exchange than on the other. However, larger packages (relative to total shares outstanding) are associated with higher costs on Nasdaq, possibly due to the greater difficulty of locating suppliers of liquidity without involving a dealer as a principal.

Finally, we stress again that our results do not address the trading costs faced by individual investors. In addition, there are other aspects of market performance beyond the magnitude of execution costs (such as the provision of research services to investors), that we do not capture in this study. 


\section{Notes}

${ }^{1} \mathrm{An}$ incomplete list of recent empirical research on comparisons between dealer and specialist markets includes Blume and Goldstein (1992), Christie and Huang (1994), Christie and Schultz (1994), Goldstein (1994), Lee (1993), Neal (1992).

${ }^{2}$ Analytical discussions include Glosten (1989), Grossman and Miller (1988), and Stoll (1985). Some of the policy implications of the debate are outlined in the Securities and Exchange Commission's Market 2000 Report (1994).

${ }^{3}$ Specialists acted as either the buyer or seller in $17.1 \%$ of 1993 NYSE share volume $(1994$ NYSE Fact Book). Madhavan and Sofianos (1994) report that for two thirds of the stocks in their sample, the specialist's purchases and sales account for less than $30 \%$ of volume. In both exchange-listed and over-the-counter issues, insitutional investors can deal directly with one another on proprietary trading systems such as Instinet and Posit. It is difficult to obtain precise figures on these systems' share of trading volume, but estimates range from $1 \%$ to $10 \%$ for NYSE volume, and about $13 \%$ for Nasdaq volume, in 1993 (Pensions \& Investments, July 25 1994).

${ }^{4}$ One measure of institutional participation is given by the volume of block trades (transactions of 10,000 shares or more): in 1992, block volume was about 51 percent of volume on the NYSE, and 45 percent of volume on Nasdaq (1993 Nasdaq Fact Book). Note, however, that trading volumes are not directly comparable across the two markets, given the greater prevalence of dealer-to-dealer trades on Nasdaq.

${ }^{5}$ For related discussions of this general issue, see Black (1986), Chan and Lakonishok (1993a) and Summers (1986).

${ }^{6}$ Alternatively, it may be more appealing to measure package size in relation to normal trading volume in the stock. Measured trading volumes are not directly comparable across the two markets, however, because of the different mix of public and dealer trading on each market. As a result, we 
work with total shares outstanding.

${ }^{7}$ It is very difficult to obtain data on the portion of the commission cost that is rebated, so our cost measures may overstate the advantage for Nasdaq. However, some idea of the potential impact of such soft-dollar rebates can be obtained as follows, based on discussions with money managers and traders. If two cents of the commission per share on the NYSE flow back to the investor, the round-trip cost is overstated by four cents per share. For the smallest stocks, with an average price of about $\$ 15$ per share, the cost is thus over-estimated by about 0.27 percent for NYSE issues. For the larger (higher-priced) stocks, the impact will be correspondingly smaller.

${ }^{8}$ Conversely, however, costs under a pre-execution benchmark may be overstated to the extent that changes in the stock price trigger trades. This may be the case if managers follow short-term positive feedback or "trend-chasing" behavior, or if they "herd" and respond in common to news.

${ }^{9}$ Keim and Madhavan (1994) evaluate trading costs for orders, using the closing price one day before the trade decision date as the benchmark. They compare average round-trip costs for NYSE and Nasdaq stocks and find that costs are higher on Nasdaq for all but the largest quintile of stocks. They also fit a regression model with a single dummy variable for Nasdaq trades, and estimate that round-trip costs on Nasdaq are higher by 0.13 percent. 


\section{References}

Black, Fischer, 1986, "Presidential Address: Noise," Journal of Finance 41, 529-543.

Blume, Marshall E., and Michael A. Goldstein, 1992, "Displayed and effective spreads by market," working paper, Rodney L. White Center for Financial Research, Wharton School, University of Pennsylvania.

Chan, Louis K. C., and Josef Lakonishok, 1993a, "Are the reports of beta's death premature?," Journal of Portfolio Management 19, 51-62.

Chan, Louis K. C., and Josef Lakonishok, 1993b, "Institutional trades and intraday stock price behavior," Journal of Financial Economics 33, 173-199.

Chan, Louis K. C., and Josef Lakonishok, 1995, "The behavior of stock prices around institutional trades," Journal of Finance 50, 1147-1174.

Christie, William G., and Roger D. Huang, 1994, "Market structures and liquidity: a transactions data study of exchange listings," Journal of Financial Intermediation 3, 300-326.

Christie, William G., and Paul H. Schultz, 1994, "Why do Nasdaq market makers avoid odd-eighth quotes?," Journal of Finance 49, 1813-1840.

Goldstein, Michael A., 1994, "A comparison of spreads and volatilities on U.S. exchanges," working paper, University of Colorado at Boulder.

Glosten, Lawrence R., 1989, "Insider trading, liquidity, and the role of the monopolist specialist," Journal of Business 62, 211-235.

Grossman, Sanford J., and Merton H. Miller, 1988, "Liquidity and market structure," Journal of Finance 43, 617-633.

Keim, Donald B., and Ananth Madhavan, 1994, "Execution costs and investment performance: An empirical analysis of institutional equity trades," working paper, Rodney L. White Center for Financial Research, Wharton School, University of Pennsylvania. 
Keim, Donald B., and Ananth Madhavan, 1995, "Anatomy of the trading process: empirical evidence on the behavior of institutional traders," Journal of Financial Economics 37, 371-398.

Lee, Charles M. C., 1993, "Market integration and price execution for NYSE-listed securities," Journal of Finance 48, 1009-1038.

Madhavan, Ananth, and George Sofianos, 1994, "Auction and dealer markets: An empirical analysis of NYSE specialist trading," working paper, New York Stock Exchange.

Morgenson, Gretchen, 1993, "Fun and games on Nasdaq," Forbes, August 16, 74-80.

Neal, Robert, 1992, "A comparison of transaction costs between competitive market maker and specialist market structures," Journal of Business 65, 317-334.

Stoll, Hans R., 1985, "The Stock Exchange specialist system: an economic analysis", Monograph Series in Finance and Economics, monograph 1985-2, Salomon Brothers Center, New York University.

Summers, Lawrence H., 1986, "Does the stock market rationally reflect fundamental values?," Journal of Finance 41, 591-601. 
Table I

Description of sample of trade packages by institutional money managers

Number of trade packages (in thousands) and dollar value traded (billions of dollars, in parentheses) for buys and sells, classified by market, in each category of firm size and in total sample. A buy (sell) package is a case where the same money management firm executed successive purchases (sales) of the same stock, with a break of less than 5 days between successive trades. The sample comprises all packages traded by 33 institutional money management firms from January 1,1989 to December 31, 1991. The classifications for firm size are based on the cut-off values from the distribution of market capitalization for NYSE stocks only. Group 1 (the smallest firms) comprises all firms with market capitalization below the 30-th percentile of the size distribution of NYSE firms; group 2 comprises firms between the 30-th and 50-th percentiles of the size distribution; group 3 comprises firms between the 50 -th and 70 -th percentiles; group 4 comprises firms between the 70-th and 90-th percentiles. Firms with equity market capitalization in excess of the 90-th percentile of the NYSE size distribution are placed in group 5.

\begin{tabular}{|c|c|c|c|c|c|c|c|c|c|c|c|c|}
\hline & \multicolumn{12}{|c|}{ Size category } \\
\hline & \multicolumn{2}{|c|}{1 (Small) } & \multicolumn{2}{|c|}{2} & \multicolumn{2}{|r|}{3} & \multicolumn{2}{|r|}{4} & \multicolumn{2}{|c|}{5 (Large) } & \multicolumn{2}{|r|}{ All } \\
\hline \multicolumn{13}{|c|}{ Panel A: Buys } \\
\hline NYSE & 5.5 & $(1.1)$ & 8.4 & (3.9) & 15.8 & (10.5) & 32.2 & $(32.0)$ & 26.5 & $(46.2)$ & 88.4 & ( 93.8) \\
\hline NASD & 20.0 & $(4.6)$ & 10.2 & $(5.6)$ & 6.2 & $(4.8)$ & 3.7 & $(4.1)$ & 0.9 & ( 1.9$)$ & 41.0 & $(21.0)$ \\
\hline AMEX & 5.3 & $(0.8)$ & 1.6 & $(0.7)$ & 1.3 & $(0.8)$ & 1.3 & $(1.0)$ & 0.1 & $(0.3)$ & 9.6 & ( 3.6$)$ \\
\hline \multicolumn{13}{|c|}{ Panel B: Sells } \\
\hline NYSE & 3.6 & $(0.9)$ & 7.1 & $(3.6)$ & 13.6 & $(10.7)$ & 27.1 & $(34.8)$ & 26.2 & $(53.6)$ & 77.6 & $(103.6)$ \\
\hline NASD & 10.7 & (3.1) & 7.6 & (4.6) & 5.0 & $(4.4)$ & 2.5 & $(3.6)$ & 0.9 & $(2.5)$ & 26.8 & ( 18.1$)$ \\
\hline AMEX & 2.7 & $(0.6)$ & 1.5 & $(0.6)$ & 1.1 & $(0.9)$ & 1.0 & $(1.0)$ & 0.1 & $(0.2)$ & 6.4 & $(3.2)$ \\
\hline
\end{tabular}


Table II

Summary statistics for institutional trade packages

Mean and selected fractiles of distribution of trade packages by institutional money managers, classified by market, for buys (sells in parentheses). A buy (sell) package is a case where the same money management firm executed successive purchases (sales) of the same stock, with a break of less than 5 days between successive trades. The sample comprises all packages traded by 33 institutional money management firms from January 1, 1989 to December 31, 1991. The classifications for firm size are based on the cut-off values from the distribution of market capitalization for NYSE stocks only. Group 1 (the smallest firms) comprises all firms with market capitalization below the 30-th percentile of the size distribution of NYSE firms; group 2 comprises firms between the 30-th and 50-th percentiles of the size distribution; group 3 comprises firms between the 50-th and 70-th percentiles; group 4 comprises firms between the 70-th and 90-th percentiles. Firms with equity market capitalization in excess of the 90 -th percentile of the NYSE size distribution are placed in group 5 .

1. Dollar value of package (Thousand $\$$ )

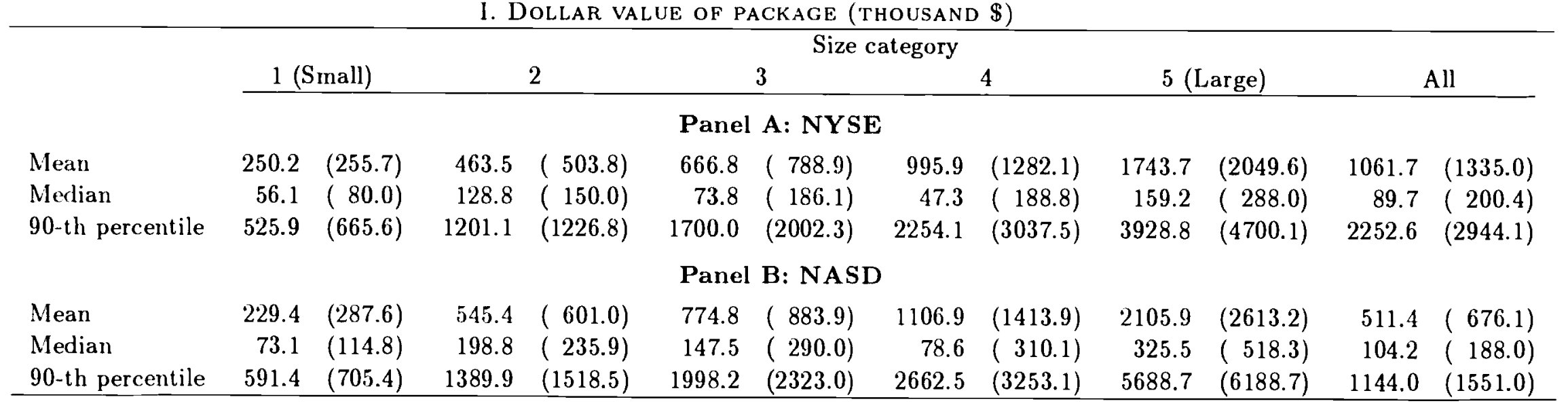


Table II (contd.)

Summary statistics for institutional trade packages

II. TRADE SIZE RELATIVE to OUTSTANDING EQUity (IN PERCENT)

\begin{tabular}{|c|c|c|c|c|c|c|c|c|c|c|c|c|}
\hline & \multicolumn{12}{|c|}{ Size category } \\
\hline & \multicolumn{2}{|c|}{1 (Small) } & \multicolumn{2}{|c|}{2} & \multicolumn{2}{|c|}{3} & \multicolumn{2}{|c|}{4} & \multicolumn{2}{|c|}{5 (Large) } & \multicolumn{2}{|c|}{ All } \\
\hline \multicolumn{13}{|c|}{ Panel A: NYSE } \\
\hline Mean & 0.28 & $(0.32)$ & 0.21 & $(0.23)$ & 0.11 & $(0.13)$ & 0.05 & $(0.07)$ & 0.02 & $(0.03)$ & 0.08 & $(0.09)$ \\
\hline Median & 0.08 & $(0.10)$ & 0.06 & $(0.07)$ & 0.01 & $(0.03)$ & 0.00 & $(0.01)$ & 0.00 & $(0.00)$ & 0.01 & $(0.01)$ \\
\hline 90 -th percentile & 0.70 & $(0.84)$ & 0.54 & $(0.55)$ & 0.30 & $(0.34)$ & 0.12 & $(0.16)$ & 0.05 & $(0.05)$ & 0.19 & $(0.22)$ \\
\hline \multicolumn{13}{|c|}{ Panel B: NASD } \\
\hline Mean & 0.43 & $(0.52)$ & 0.27 & $(0.29)$ & 0.15 & $(0.17)$ & 0.07 & $(0.09)$ & 0.03 & $(0.04)$ & 0.23 & $(0.26)$ \\
\hline Median & 0.15 & $(0.22)$ & 0.10 & $(0.12)$ & 0.03 & $(0.05)$ & 0.00 & $(0.02)$ & 0.01 & $(0.01)$ & 0.06 & $(0.07)$ \\
\hline 90-th percentile & 1.07 & $(1.28)$ & 0.68 & $(0.74)$ & 0.39 & $(0.44)$ & 0.15 & $(0.21)$ & 0.09 & $(0.11)$ & 0.54 & $(0.61)$ \\
\hline
\end{tabular}


Table II (contd.)

Summary statistics for institutional trade packages

III. Package duration (IN Days)

\begin{tabular}{|c|c|c|c|c|c|c|c|c|c|c|c|c|}
\hline & \multicolumn{12}{|c|}{ Size category } \\
\hline & \multicolumn{2}{|c|}{1 (Srnall) } & \multicolumn{2}{|r|}{2} & \multicolumn{2}{|r|}{3} & \multicolumn{2}{|c|}{4} & \multicolumn{2}{|c|}{5 (Large) } & \multicolumn{2}{|c|}{ All } \\
\hline \multicolumn{13}{|c|}{ Panel A: NYSE } \\
\hline Mean & 2.32 & $(2.20)$ & 2.21 & $(2.24)$ & 1.91 & $(2.02)$ & 1.90 & $(1.85)$ & 2.31 & $(1.93)$ & 2.08 & $(1.96)$ \\
\hline Median & 1.13 & $(1.00)$ & 1.00 & $(1.00)$ & 1.00 & $(1.00)$ & 1.00 & $(1.00)$ & 1.00 & $(1.00)$ & 1.00 & $(1.00)$ \\
\hline 90 -th percentile & 5.03 & $(4.95)$ & 4.71 & $(4.80)$ & 4.05 & $(4.31)$ & 3.94 & $(3.77)$ & 4.79 & $(3.98)$ & 4.39 & $(4.10)$ \\
\hline \multicolumn{13}{|c|}{ Panel B: NASD } \\
\hline Mean & 1.83 & $(2.12)$ & 1.94 & $(2.03)$ & 1.80 & $(1.91)$ & 1.96 & $(1.76)$ & 2.50 & $(1.83)$ & 1.88 & $(2.01)$ \\
\hline Median & 1.00 & $(1.00)$ & 1.00 & $(1.00)$ & 1.00 & $(1.00)$ & 1.00 & $(1.00)$ & 1.00 & $(1.00)$ & 1.00 & $(1.00)$ \\
\hline 90-th percentile & 3.69 & $(4.64)$ & 4.03 & $(4.41)$ & 3.63 & $(3.95)$ & 4.07 & $(3.59)$ & 4.90 & $(3.83)$ & 3.83 & $(4.34)$ \\
\hline
\end{tabular}


Table III.

Number of packages and dollar value traded by institutional money managers, classified by firm size and trade complexity, 1989-1991.

This table reports the number of trade packages (in thousands) and dollar value traded (in parentheses, in billions of dollars) on each market in each category of firm size and trade complexity. Packages are classified by firm size and trade complexity. There are 5 classes by firm size (outstanding equity market value at the end of the prior quarter for the stock being traded). ${ }^{1}$ Within each size group, packages are classified into one of 5 groups by trade complexity (package size relative to outstanding equity).$^{2}$ A buy (sell) package is a case where the same money management firm executed successive purchases (sales) of the same stock, with a break of less than 5 days between successive trades. The sample comprises all trades by 33 institutional money management firms from January 1, 1989 to December $31,1991$.

\begin{tabular}{|l|cccccc|}
\hline \multicolumn{7}{c}{ PANEL A: NYSE } \\
\hline Complexity 1 (Easy) & 1 (Small) & 2 & 3 & 4 & 5 (Large) & All firms \\
& 5.6 & 8.8 & 15.7 & 30.2 & 26.6 & 86.9 \\
Complexity 2 & $(0.2)$ & $(0.6)$ & $(0.7)$ & $(1.2)$ & $(3.0)$ & $(5.7)$ \\
& 1.9 & 3.6 & 7.1 & 15.0 & 13.2 & 40.8 \\
Complexity 3 & $(0.4)$ & $(1.3)$ & $(2.5)$ & $(5.2)$ & $(10.0)$ & $(19.4)$ \\
& 1.1 & 1.9 & 4.0 & 8.5 & 7.9 & 23.4 \\
Complexity 4 & $(0.6)$ & $(1.9)$ & $(4.8)$ & $(12.9)$ & $(20.7)$ & $(40.9)$ \\
& 0.3 & 0.6 & 1.3 & 2.8 & 2.5 & 7.5 \\
Complexity 5 (Difficult) & $(0.3)$ & $(1.1)$ & $(3.7)$ & $(11.6)$ & $(16.3)$ & $(33.0)$ \\
& 0.2 & 0.6 & 1.3 & 2.8 & 2.5 & 7.4 \\
All packages & $(0.5)$ & $(2.6)$ & $(9.5)$ & $(35.9)$ & $(49.8)$ & $(98.3)$ \\
& 9.1 & 15.5 & 29.4 & 59.3 & 52.7 & \\
& $(2.0)$ & $(7.5)$ & $(21.2)$ & $(66.8)$ & $(99.8)$ & \\
\hline
\end{tabular}

PANel B: NasdaQ

\begin{tabular}{|l|cccccc|}
\hline & 1 (Small) & 2 & 3 & 4 & 5 (Large) & All firms \\
\hline Complexity 1 (Easy) & 14.0 & 7.9 & 4.7 & 2.6 & 0.7 & 29.9 \\
& $(0.6)$ & $(0.6)$ & $(0.2)$ & $(0.1)$ & $(0.1)$ & $(1.6)$ \\
Complexity 2 & 8.5 & 4.9 & 3.1 & 1.6 & 0.5 & 18.6 \\
& $(1.3)$ & $(1.6)$ & $(1.0)$ & $(0.5)$ & $(0.2)$ & $(4.6)$ \\
Complexity 3 & 5.0 & 3.0 & 2.0 & 1.2 & 0.4 & 11.6 \\
& $(2.0)$ & $(2.7)$ & $(2.2)$ & $(1.6)$ & $(0.7)$ & $(9.2)$ \\
Complexity 4 & 1.6 & 1.0 & 0.7 & 0.4 & 0.1 & 3.8 \\
& $(1.3)$ & $(1.7)$ & $(1.8)$ & $(1.4)$ & $(0.7)$ & $(6.9)$ \\
Complexity 5 (Difficult) & 1.6 & 1.0 & 0.7 & 0.4 & 0.1 & 3.8 \\
& $(2.5)$ & $(3.6)$ & $(4.0)$ & $(4.1)$ & $(2.7)$ & $(16.9)$ \\
All packages & 30.7 & 17.8 & 11.2 & 6.2 & 1.8 & \\
& $(7.7)$ & $(10.2)$ & $(9.2)$ & $(7.7)$ & $(4.4)$ & \\
\hline
\end{tabular}

\footnotetext{
'The classifications for firm size are based on the cut-off values from the distribution of market capitalization for NYSE stocks only. Group 1 (the smallest firms) comprises all firms with market capitalization below the 30 -th percentile of the size distribution of NYSE firms; group 2 comprises firms between the 30-th and 50-th percentiles of the size distribution; group 3 comprises firms between the 50-th and 70-th percentiles; group 4 comprises firms between the 70-th and 90-th percentiles. Firms with equity market capitalization in excess of the 90-th percentile of the NYSE size distribution are placed in group 5.

${ }^{2}$ In each size class, complexity group 1 ("easy" packages) includes packages ranked below the median when sorted by relative package size; group 2 comprises packages whose relative size falls between the median and the third quartile; group 3 comprises packages whose relative size falls between the third and the 90-th percentile; group 4 comprises packages whose relative size falls between the 90 -th and 95 -fifth percentiles. Group 5 ("difficult" packages) contains the largest five percent of packages when ranked by relative size.
} 


\section{Table IV.}

Round-trip execution cost, in percent, for NYSE and Nasdaq packages, classified by size and complexity, 1989-1991.( (+) means cost, $(-)$ means gain )

This table reports the median round-trip (buy and sell) execution cost (price impact and commission cost), in percent, across NYSE and Nasdaq trade packages, where packages are classified by firm size and trade complexity. There are 5 classes by firm size (outstanding equity market value at the end of the prior quarter for the stock being traded). ${ }^{1}$ Within each size group, packages are classified into one of 5 groups by trade complexity (package size relative to outstanding equity). ${ }^{2}$ A buy (sell) package is a case where the same money management firm executed successive purchases (sales) of the same stock, with a break of less than 5 days between successive trades. The sample comprises all trades by 33 institutional money management firms from January 1, 1989 to December 31, 1991. An asterisk in a particular size-complexity category indicates the cost is lower than the corresponding category on the other market.

\begin{tabular}{|c|c|c|c|c|c|c|}
\hline IEL A: & 1 (Small) & 2 & 3 & 4 & 5 (Large) & Row average \\
\hline \multicolumn{7}{|c|}{ NYSE } \\
\hline Complexity 1 (Easy) & 2.10 & 1.24 & $0.78^{*}$ & $0.52^{*}$ & $0.40^{*}$ & 1.01 \\
\hline Complexity 2 & 2.86 & $1.09^{*}$ & 1.04 & 0.77 & 0.50 & 1.25 \\
\hline Complexity 3 & 3.19 & 1.92 & 1.06 & $0.89^{*}$ & $0.71^{*}$ & 1.55 \\
\hline Complexity 4 & 3.57 & $1.63^{*}$ & 1.64 & $1.03^{*}$ & $1.28^{*}$ & 1.83 \\
\hline Complexity 5 (Difficult) & 4.85 & $2.00^{*}$ & 2.41 & $1.07^{*}$ & $1.63^{*}$ & $2.39^{*}$ \\
\hline Column average & 3.31 & $1.58^{*}$ & 1.39 & $0.86^{*}$ & $0.90^{*}$ & \\
\hline \multicolumn{7}{|c|}{ Nasdaq } \\
\hline Complexity 1 (Easy) & $0.85^{*}$ & $0.83^{*}$ & 0.82 & 0.56 & 0.77 & $0.77^{*}$ \\
\hline Complexity 2 & $2.45^{*}$ & 1.45 & $0.95^{*}$ & $0.65^{*}$ & $0.47^{*}$ & $1.19^{*}$ \\
\hline Complexity 3 & $1.97^{*}$ & $1.52^{\star}$ & $0.93^{*}$ & 1.20 & 1.09 & $1.34^{*}$ \\
\hline Complexity 4 & $2.05^{*}$ & 1.83 & $0.86^{*}$ & 1.97 & 1.86 & $1.71^{*}$ \\
\hline Complexity 5 (Difficult) & $3.78^{*}$ & 2.88 & $1.89^{*}$ & 1.75 & 1.94 & 2.45 \\
\hline Column average & $2.22^{*}$ & 1.70 & $1.09^{*}$ & 1.23 & 1.23 & \\
\hline
\end{tabular}

PANEL B: POST-EXECUTION BENCHMARK: ClOSING PRICE FIVE DAYS AFTER PACKAGE'S LAST
\begin{tabular}{|l|ccccccc|}
\hline & 1 (Small) & 2 & 3 & 4 & 5 (Large) & Row average \\
\hline & \multicolumn{7}{c}{ NYSE } \\
Complexity 1 (Easy) & 1.14 & 0.39 & 0.51 & $0.27^{*}$ & $0.42^{*}$ & 0.55 \\
Complexity 2 & 0.81 & 0.54 & -0.06 & 0.35 & $0.37^{*}$ & 0.40 \\
Complexity 3 & 0.35 & 0.17 & $0.13^{*}$ & 0.04 & 0.06 & 0.15 \\
Complexity 4 & $1.23^{*}$ & -0.11 & $-0.32^{*}$ & $-0.13^{*}$ & $0.17^{*}$ & $0.17^{*}$ \\
Complexity 5 (Difficult) & 2.95 & 0.60 & $-0.73^{*}$ & 0.68 & $-0.04^{*}$ & 0.69 \\
Column average & 1.30 & 0.32 & $-0.09^{*}$ & 0.24 & $0.20^{*}$ & \\
\hline & & \multicolumn{7}{c}{ Nasdaq } & & & \\
Complexity 1 (Easy) & $0.08^{*}$ & $-0.04^{*}$ & $-0.23^{*}$ & 0.59 & 1.68 & $0.42^{*}$ \\
Complexity 2 & $0.48^{*}$ & $-0.48^{*}$ & $-0.22^{*}$ & $-0.71^{*}$ & 0.56 & $-0.07^{*}$ \\
Complexity 3 & $-0.25^{*}$ & $-1.13^{*}$ & 0.15 & $-1.05^{*}$ & $-0.14^{*}$ & $-0.48^{*}$ \\
Complexity 4 & 1.29 & $-1.43^{*}$ & 0.61 & 0.16 & 0.23 & 0.17 \\
Complexity 5 (Difficult) & $0.89^{*}$ & $-0.17^{*}$ & 1.08 & $0.25^{*}$ & 0.35 & $0.48^{*}$ \\
Column average & $0.50^{*}$ & $-0.65^{*}$ & 0.28 & $-0.15^{*}$ & 0.54 & \\
\hline
\end{tabular}

\footnotetext{
${ }^{1}$ The classifications for firm size are based on the cut-off values from the distribution of market capitalization for NYSE stocks only. Group 1 (the smallest firms) comprises all firms with market capitalization below the 30-th percentile of the size distribution of NYSE firms; group 2 comprises firms between the 30-th and 50-th percentiles of the size distribution; group 3 comprises firms between the 50-th and 70-th percentiles; group 4 comprises firms between the 70-th and 90-th percentiles. Firms with equity market capitalization in excess of the 90-th percentile of the NYSE size distribution are placed in group 5.

${ }^{2}$ In each size class, complexity group 1 ("easy" packages) includes packages ranked below the median when sorted by relative package size; group 2 comprises packages whose relative size falls between the median and the third quartile; group 3 comprises packages whose relative size falls between the third and the 90-th percentile; group 4 comprises packages whose relative size falls between the 90-th and 95-fifth percentiles. Group 5 ("difficult" packages) contains the largest five percent of packages when ranked by relative size.
} 
Table V.

Difference in round-trip execution cost, in percent, between NYSE and Nasdaq packages matched by investment management firm, classified by size and complexity, 1989-1991.

This table reports the median difference between NYSE and Nasdaq with respect to round-trip (buy and sell) execution cost (price impact and commission cost) in percent, for trade packages by the same money management firm. Packages are classified by firm size and trade complexity. There are 5 classes by firm size (outstanding equity market value at the end of the prior quarter for the stock being traded).' Within each size group, packages are classified into one of 5 groups by trade complexity (package size relative to outstanding equity). ${ }^{2}$ Within each size-complexity category, the difference between the median cost for NYSE and the median cost for Nasdaq packages is calculated for each manager with at least 10 packages in that category, and trading on both markets. The tabulated entry represents the median over all managers in that category of the median cost differences (NYSE - Nasdaq). A buy (sell) package is a case where the same money management firm executed successive purchases (sales) of the same stock, with a break of less than 5 days between successive trades. The sample comprises all trades by 33 institutional money management firms from January 1, 1989 to December $31,1991$.

\begin{tabular}{|c|c|c|c|c|c|c|}
\hline ANEL A: PRE-EXECUTIO & 1(Small) & 2 & 3 & 4 & 5(Large) & Row average \\
\hline \multicolumn{7}{|c|}{$(+)$ means Nasdaq cost is lower } \\
\hline Complexity 1 (Easy) & 0.71 & 0.61 & 0.05 & 0.02 & -0.45 & 0.19 \\
\hline Complexity 2 & 0.56 & 0.40 & 0.00 & -0.15 & -0.05 & 0.15 \\
\hline Complexity 3 & 0.74 & 0.50 & -0.31 & -0.15 & -0.50 & 0.06 \\
\hline Complexity 4 & 0.81 & -0.14 & 0.54 & -0.70 & -0.51 & 0.00 \\
\hline Complexity 5 (Difficult) & 0.60 & -0.01 & 0.42 & -0.63 & -0.88 & -0.10 \\
\hline Column average & 0.68 & 0.27 & 0.14 & -0.32 & -0.48 & \\
\hline
\end{tabular}

Panel B: Post-execution Benchmark: Closing PRice five days after paCkaGe's last

\begin{tabular}{|c|c|c|c|c|c|c|}
\hline \multicolumn{7}{|c|}{ DAY } \\
\hline & 1(Small) & 2 & 3 & 4 & 5(Large) & Row average \\
\hline \multicolumn{7}{|c|}{$(+)$ means Nasdaq cost is lower } \\
\hline Complexity 1 (Easy) & 0.79 & 0.39 & 0.89 & -0.27 & -1.02 & 0.16 \\
\hline Complexity 2 & 0.24 & 1.32 & 0.01 & 0.98 & -0.37 & 0.44 \\
\hline Complexity 3 & 0.03 & 1.37 & 0.37 & 0.97 & 0.16 & 0.58 \\
\hline Complexity 4 & -0.54 & 1.17 & 0.00 & 0.25 & 1.65 & 0.51 \\
\hline Complexity 5 (Difficult) & 0.47 & 0.96 & -0.55 & 1.19 & -1.14 & 0.19 \\
\hline Column average & 0.20 & 1.04 & 0.14 & 0.62 & -0.14 & \\
\hline
\end{tabular}

\footnotetext{
${ }^{1}$ The classifications for firm size are based on the cut-off values from the distribution of market capitalization for NYSE stocks only. Group 1 (the smallest firms) comprises all firms with market capitalization below the 30-th percentile of the size distribution of NYSE firms; group 2 comprises firms between the 30-th and 50-th percentiles of the size distribution; group 3 comprises firms between the 50-th and 70-th percentiles; group 4 comprises firms between the 70-th and 90-th percentiles. Firms with equity market capitalization in excess of the 90-th percentile of the NYSE size distribution are placed in group 5 .

${ }^{2}$ In each size class, complexity group 1 ("easy" packages) includes packages ranked below the median when sorted by relative package size; group 2 comprises packages whose relative size falls between the median and the third quartile; group 3 comprises packages whose relative size falls between the third and the 90-th percentile; group 4 comprises packages whose relative size falls between the 90-th and 95-fifth percentiles. Group 5 ("difficult" packages) contains the largest five percent of packages when ranked by relative size.
} 
Table VI.

Regression evidence on difference in round-trip execution cost, in percent, between NYSE and Nasdaq, 1989-1991.

The regression is

$$
\begin{aligned}
c_{i}= & \alpha_{0}+\beta \text { LOGSIZ }_{i}+\gamma \text { COMP }_{i}+\sum_{j=2}^{33} \delta_{j} M_{i j} \\
& +\sum_{g} \phi_{j} \text { IND }_{i j}+\pi_{1} \text { LOGP }_{i}+\pi_{2} \text { VOL }_{i}+\pi_{3} \text { DUR }_{i} \\
& +\sum_{j=1}^{9} \alpha_{j} \text { NASD }_{i j}+\epsilon_{i}
\end{aligned}
$$

where $c_{i}$ is the cost (in percent) for the $i$-th package. LOGSIZ is the logarithm of the equity market capitalization at the beginning of the quarter of the stock traded, and COMP $i$ denotes the size of the package relative to shares outstanding at the beginning of the quarter. The dumnyy variables $M_{i j}$ are manager-specific effects. The stock's industry affiliation is given by dummy variables $\mathrm{IND}_{i j}$ for 2-digit SIC code classifications; LOGP, is the logarithm of the stock price at the beginning of the quarter; VOL $i$ is the volatility of the underlying stock traded (measured as the standard deviation of daily returns over the prior quarter); and $D U R_{i}$ is package duration. There are nine dummy variables capturing the effect of exchange affiliation: there are three categories of firm size (small, medium and large); within each size category, packages are classified as easy, moderate and difficult. ${ }^{1}$ Within each of the resulting nine categories, the dummy variable for the exchange, $\mathrm{NASD}_{i j}$, takes a value of one if the package is for a Nasdaq issue and zero otherwise.

The equation is fit separately for purchases and sales. The coefficient of each variable is added across the equation for buys and for sells to give the effect on the cost of a round-trip (buy and sell) transaction. The sample comprises all packages traded by 33 institutional money management firms from January 1, 1989 to December 31, 1991. A buy (sell) package is a case where the same money management firm executed successive purchases (sales) of the same stock, with a break of less than 5 days between successive trades.

Panel A reports the coefficients on a round-trip basis for the non-excliange variables (excluding the industry and manager effects). Panel B reports the round-trip coefficients of the dummy variables for the exchange effect. In panel $\mathrm{C}$, the regression is fitted separately over the first half of the sample period (January 1989 to June 1990) and over the second half of the period (July 1990 to December 1991). The round-trip coefficients of the dummy variables for the exchange effect are reported for each subperiod.

\begin{tabular}{l|c|c|} 
PANEL A: EFFECTS OF NON-EXCHANGE VARIABLES \\
\hline \multicolumn{1}{|c|}{ Variable } & $\begin{array}{c}\text { Pre-execution } \\
\text { Benchmark }\end{array}$ & $\begin{array}{c}\text { Post-execution } \\
\text { Benchmark }\end{array}$ \\
\hline Log firm size & -0.30 & -0.09 \\
Relative package size & 12.60 & 35.57 \\
Log stock price & 0.30 & -0.35 \\
Package duration & 0.08 & -0.01 \\
Standard deviation & 5.78 & 4.26 \\
\hline
\end{tabular}

\footnotetext{
${ }^{1}$ The classifications for firm size are based on the cut-off values from the distribution of market capitalization for NYSE stocks only. "Small" firms include all firms with market capitalization below the 50-th percentile of the size distribution of NYSE firms; "medium" firms denote firms between the 50-th and 70-th percentiles of the size distribution; firms with equity market capitalization in excess of the 70-th percentile of the NYSE size distribution are placed in the category of "large" firms.

Within each size group, packages are classified into one of 3 groups by trade complexity (package size relative to outstanding equity). In each size class, "easy" packages include packages ranked below the 75-th percentile when sorted by relative package size; "moderate" packages denote packages whose relative size falls between the third quartile and the 90-th percentile; "difficult" packages are the largest ten percent of packages when ranked by relative size.
} 
Table VI (continued)

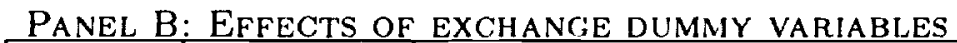

\begin{tabular}{|c|c|c|c|}
\hline $\begin{array}{l}\text { Firm } \\
\text { Size }\end{array}$ & $\begin{array}{c}\text { Package } \\
\text { Complexity }\end{array}$ & $\begin{array}{c}\text { Pre-execution } \\
\text { Benchmark }\end{array}$ & $\begin{array}{c}\text { Post-execution } \\
\text { Benchmark }\end{array}$ \\
\hline \multicolumn{4}{|c|}{$(+)$ means Nasdaq cost is higher } \\
\hline \multirow[t]{3}{*}{ Small } & Easy & -0.25 & -0.40 \\
\hline & Moderate & 0.43 & -0.39 \\
\hline & Difficult & 1.28 & -0.28 \\
\hline \multirow[t]{3}{*}{ Medium } & Easy & -0.14 & -0.29 \\
\hline & Moderate & -0.19 & -0.47 \\
\hline & Difficult & 1.26 & 0.34 \\
\hline \multirow[t]{3}{*}{ Large } & Easy & -0.09 & 0.13 \\
\hline & Moderate & -0.19 & -0.43 \\
\hline & Difficult & 1.23 & -0.50 \\
\hline
\end{tabular}

PANel C: EfFECTS OF EXCHANGE DUMmy VARIABLES, BY SUBPERIOD

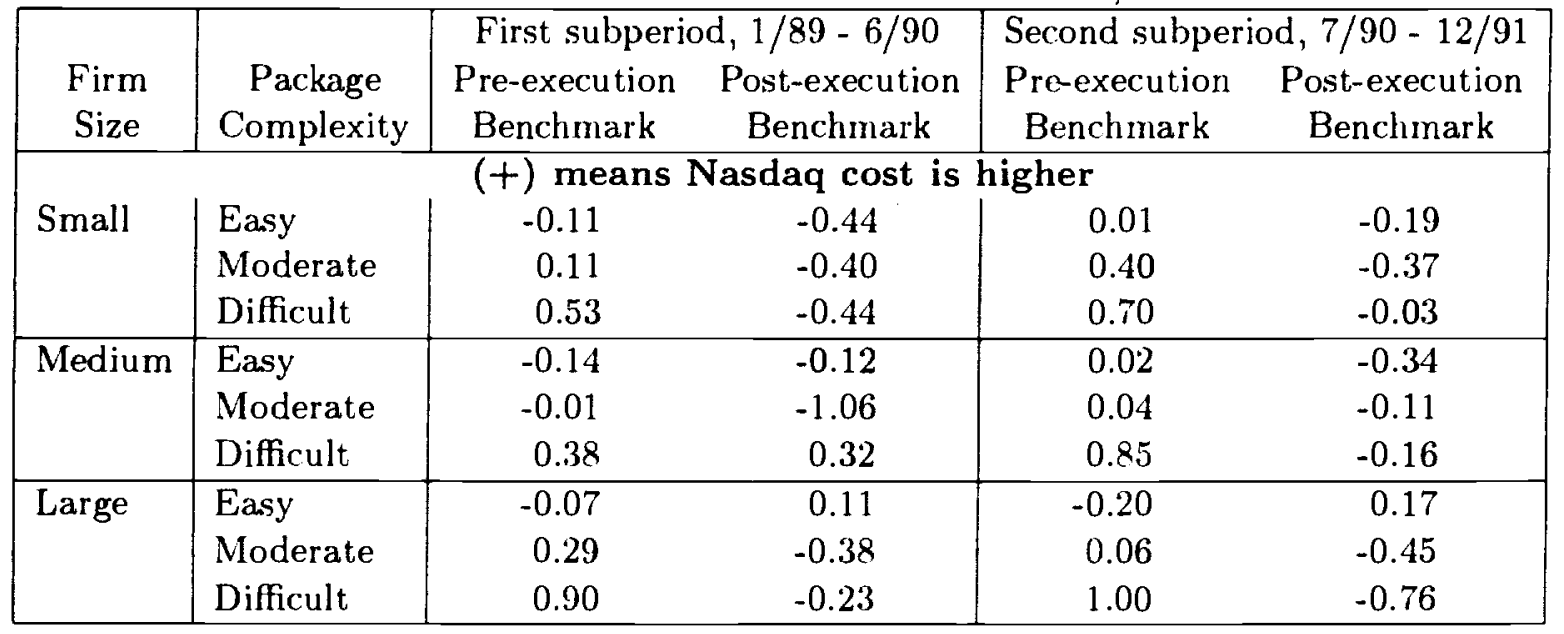


Table VII.

Difference in round-trip execution cost, in percent, between NYSE and Nasdaq, by money managers.

The following regression is fit for each money management firm's buy or sell packages:

$$
\begin{aligned}
c_{i}= & \alpha_{m 0}+\beta_{m} \text { LOGSIZ }_{i}+\gamma_{m} \text { COMP }_{i} \\
& +\sum \phi_{m j} \text { LND }_{i j}+\pi_{m 1} \text { LOGP }_{i}+\pi_{m 2} \text { VOL }_{i}+\pi_{m 3} \text { DUR }_{i} \\
& +\alpha_{m 1} \text { NASD }_{i}+\epsilon_{m i}
\end{aligned}
$$

where the subscript $m$ denotes the money management firm, and $c_{i}$ is the cost (in percent) for the i-th package executed by this money manager. LOGSIZ $i$ is the logarithm of the equity market capitalization at the beginning of the quarter of the stock traded, and COMP $i$ denotes the size of the package relative to shares outstanding at the beginning of the quarter. The stock's industry affiliation is given by dummy variables IND $_{i j}$ for 2 -digit SIC code classifications; LOGP $i$ is the logarithm of the stock price at the beginning of the quarter; VOL $i$ is the volatility of the underlying stock traded (measured as the standard deviation of daily returns over the prior quarter); and DUR $i$ is package duration. The dummy variable $\mathrm{NASD}_{i}$ captures the effect of exchange affiliation, and takes the value of one if the $\mathrm{i}$-th package is for a Nasdaq issue (zero otherwise).

The equation is fit separately for each money manager's purchases and sales. The coefficient of the dummy variable for exchange, $\alpha_{m 1}$, is then added across each manager's equation for buys and for sells to give the difference in that manager's round-trip (buy and sell) cost across the two exchanges. This table reports summary statistics for the distribution of this round-trip coefficient across the sample of 33 money managers. The sample comprises all packages traded by 33 institutional money management firms from January 1, 1989 to December 31, 1991. A buy (sell) package is a case where the same money management firm executed successive purchases (sales) of the same stock, with a break of less than 5 days between successive trades.

\begin{tabular}{|l|cc|}
\hline & $\begin{array}{c}\text { Pre-execution } \\
\text { Benchmark }\end{array}$ & $\begin{array}{c}\text { Post-execution } \\
\text { Benchmark }\end{array}$ \\
\hline \multicolumn{2}{|c|}{$(+)$ means Nasdaq cost is higher } \\
Mean & 0.16 & -0.12 \\
Standard deviation & 0.39 & 0.70 \\
Median & 0.13 & 0.02 \\
10-th percentile & -0.25 & -0.86 \\
25-th percentile & -0.20 & -0.41 \\
75-th percentile & 0.44 & 0.30 \\
90-th percentile & 0.60 & 0.51 \\
Number $>0$ & 21 & 17 \\
Number $\leq 0$ & 12 & 16 \\
\hline
\end{tabular}

